\title{
Prevalence of overweight and obesity in students from different altitudinal zones of Jujuy according to three international references (IOTF, CDC and WHO)
}

\author{
Elena Meyer, M.D. ${ }^{a}$, Rafael Carrillo, Technician ${ }^{b}$, Estela María Román, B.S. ${ }^{b}$, \\ Ignacio Felipe Bejarano, B.S. ${ }^{b}$, Emma Laura Alfaro, M.D. ${ }^{b}$, \\ and José Edgardo Dipierri, Magister ${ }^{b}$
}

\begin{abstract}
Introduction. Prevalences of overweight and obesity in students from different altitudinal zones of Jujuy are compared using the International Obesity Task Force (IOTF), the Centers for Disease Control(CDC) and the World Health Organization (WHO) references, and the agreement among them.

Material and Methods. Weight and height data from 15541 students were grouped in highlands (HL) ( $\geq 2500$ MASL) and lowlands (LL) $(<2500$ MASL) and in two age groups (5-6.99 years old and 11-12.99 years old). Overweight and obesity prevalences were calculated according to the different references. The differences in outcome measures and prevalences were established using the $\chi^{2}$ test and the $t$ test, and agreement among the criteria was calculated using the kappa index.

Results. Students from the HL had lower weight, height and body mass index (BMI) values $(p<0.05)$. Overweight and obesity prevalences compared to the WHO reference were higher, except for overweight in students of both sexes, from 11 to 12.99 years old, from the HL and the LL. Regardless of the references, gender and age, overweight and obesity prevalences were generally higher in the LL. Agreement between the IOTF and the CDC was good-very good, and agreement among them and the WHO was fair-moderate.

Conclusions. Students from the HL had a lower overweight and obesity prevalence. The greatest agreement was observed between the IOTF and the CDC references.

Key words: obesity, overweight, references, students, altitudinal zonation.
\end{abstract}

http:/ /dx.doi.org/10.5546/aap.2013.516

b. Altitude Biology Institute, Universidad

Nacional de Jujuy.

Correspondence:

Elena Meyer, M.D. prosanejujuy@gmail. com

Conflict of interest: None.

Received: 10-11-2012 Accepted: 07-03-2013 worldwide, with a variation in the secular trend observed in different countries. ${ }^{1}$ Based on OB prevalence observed in the Americas between 1985 and 2005, it was estimated that by 2010 OB prevalence would be $15 \%$ and overweight (OW) prevalence $40 \%{ }^{2}$ In Argentina, it has been observed that $5.4 \%$ of patients attending a pediatric consultation (10-19 year old patients) are obese and $20.8 \%$ are overweight. ${ }^{3}$ In 2007, OB and OW prevalences among Argentine students were $2.6 \%$ and $19 \%$, respectively. ${ }^{4}$ In San Salvador de Jujuy, between 1995 and 2000, different assessment criteria allowed to establish that $\mathrm{OB}$ and $\mathrm{OW}$ prevalences among students were over $4 \%$ and $13 \%$, in that order. ${ }^{5}$

Given that the body mass index (BMI) can be easily measured and is highly correlated to body fat, it is the most commonly used parameter for assessing this type of fat in children and adolescents. ${ }^{6}$ Three references were used to define overweight and obesity as per the BMI of children population: IOTF, ${ }^{7} \mathrm{CDC}^{8}$ and $\mathrm{WHO} .{ }^{9}$ However, several studies have indicated that these references provide varying results in relation to $\mathrm{OB}$ and OW prevalence..$^{10-14}$ Such differences could influence public policies, and OW and OB prevention and early detection programs. ${ }^{15}$

BMI reveals a positive association with fat and height in children and adolescents; ${ }^{16,17}$ for this reason, classifying a child in one or other category, and the resulting $\mathrm{OB}$ and OW prevalence could vary depending on their height. 
The population in Jujuy has settled at different altitudinal zones (350-4000 MASL). The populations in the highlands (HL), i.e., at or above $2500 \mathrm{MASL}$, are characterized by having an adaptive response to the environmental conditions typical of the HL (hypoxia, low temperature, little humidity, and limited food resources), a lower height than populations in the lowlands (LL), closer to the sea level. ${ }^{5}$ In addition, populations in the HL have higher percentages of unmet basic needs (UBNs) (33.6\%) and a high child mortality rate (17/1000 live newborns). By contrast, the LL, home to the capital city of Jujuy, have a more favorable weather, lower percentages of UBNs $(2-3 \%)$ and a child mortality rate of $13 / 1000$ live newborns.

Estimates of $\mathrm{OW}, \mathrm{OB}$ and $\mathrm{OW}+\mathrm{OB}$ prevalences in students from different altitudinal zones of Jujuy are compared using the IOTF, CDC and WHO cutoff values, and the agreement among such references.

\section{MATERIAL AND METHODS}

This was a cross-sectional, ecogeographic study. Weight and height data were obtained from assessments made in first to sixth grade students from Jujuy between 2010 and 2011 in the context of the School Health Program (Programa de Sanidad Escolar, PROSANE) ${ }_{1}^{18}$ which depends on the Ministry of Health of Jujuy. The PROSANE is a national program targeted at assessing the health status of school-aged children, monitoring healthcare provided for any health problem detected, and implementing health promotion and prevention actions in schools. ${ }^{18}$ The program aims at assessing children at the initiation and at the end of their primary school courses, i.e., first and sixth grades. Such time points were chosen because at 6 and 11 years old, the most common ages for these groups, they complete their immunization schedule. The sample was made up of all students assessed by the program's Jujuy teams in the different areas of the province.

Height and weight were recorded according to the PROSANE Implementation Manual, using a standing scale and a stadiometer attached to the wall in primary care facilities, by trained personnel, who were coordinated by PROSANE Jujuy.

Weight and height data were grouped according to the geographic location of schools: highlands (HL) ( $\geq 2500$ MASL) and lowlands (LL) $(<2500$ MASL).

Two age groups were established: from 5 to 6.99 years old and from 11 to 12.99 years old. The body mass index was calculated (BMI= weight $[\mathrm{kg}] /$ height $\left.^{2}[\mathrm{~m}]\right)$. Students were classified as overweight or obese according to the IOTF, CDC and $\mathrm{WHO}$ cutoff values.

$\mathrm{OW}, \mathrm{OB}$ and $\mathrm{OW}+\mathrm{OB}$ prevalences, and the prevalence percentage differences among references, were calculated by gender, age and geographic region. The statistical significance of differences among the prevalences by gender, age and origin was established using the 2 test, while that of height, weight and BMI was calculated using the $t$ test. The agreement between the OW and OB criteria was assessed using the kappa (k) index calculated with the SPSS version 17.0 statistical package, and classified as poor ( $\leq 0.20)$, fair (0.20-0.40), moderate (0.41-0.60), good $(0.61-0.80)$ or very good $(>0.80) .{ }^{19}$

\section{RESULTS}

A total of 15541 students were assessed. Table 1 shows the number of surveyed target schools and the percentage of census population by geographic altitude and age group.

In both genders and age groups, students from the HL had a lower weight, height and BMI; and differences were significant (Tables 2 and 3). Regardless of the reference used for both genders and age groups, OW, OB and $\mathrm{OW}+\mathrm{OB}$ prevalences were higher in the LL; and differences were significant in most comparisons (Tables 2 and 3).

When analyzing $\mathrm{OW}, \mathrm{OB}$ and $\mathrm{OW}+\mathrm{OB}$ prevalences estimated with the different references, in general it is observed that the WHO prevalences were higher (Table 2 and 3). The exception is seen in OW prevalence in 11-12.99 year old boys (Table 2) and girls (Table 3) from the HL and LL, in which the highest prevalence is obtained with the IOTF reference.

When comparing the references, in the case of $\mathrm{OW}$, the statistical significance varies by gender, age and origin, without any differences in the 5-6.99 year old girls from the HL and LL, the 5-6.99 year old boys from the HL, and the 1112.99 year old boys and girls from the HL (Tables 4 and 5). In the case of $\mathrm{OB}$, the differences among the references were significant in all comparisons, except between the IOTF/CDCin both genders and age groups from the HL (Tables 4 and 5). In relation to $\mathrm{OW}+\mathrm{OB}$, a similar pattern was observed, with an exception also found in the LL groups (Tables 4 and 5).

The agreement among the references ranged from good to very good for the IOTF and the CDC, depending on students' gender, age and 
TABLE 1. Sample characteristics

\begin{tabular}{lccc}
\hline Characteristic & HL & LL & Jujuy \\
\hline $\begin{array}{l}\text { Number of target schools* } \\
\text { Number of surveyed schools (included in this study) }\end{array}$ & 112 & 265 & 377 \\
$\begin{array}{l}\text { Number of 5-6.99 year old children } \\
\text { (\% of the census population within this age range* })\end{array}$ & 20 & 198 & 218 \\
$\begin{array}{l}\text { Number of 11-12.99 year old children } \\
\text { (\% of the census population within this age range }\end{array}$ & $410(15.6)$ & $6320(28)$ & $6730(26.7)$ \\
Percentage sampled of the census population aged (5, 6, 11 and 12 years old) ${ }^{* *}$ & $570(19.1)$ & $8241(30.6)$ & $8811(29.2)$ \\
\hline
\end{tabular}

*PROSANE Jujuy; **2010 census.

HL: Highlands. LL: Lowlands.

TABLE 2. Mean and standard deviation for weight, height and BMI, and prevalence (\%) of overweight (OW), obesity (OB) and $\mathrm{OW}+\mathrm{OB}$ as per the references for age and origin in boys

\begin{tabular}{|c|c|c|c|c|c|c|}
\hline \multirow{3}{*}{$\begin{array}{l}\text { Age } \\
\text { Origin } \\
n\end{array}$} & \multicolumn{3}{|c|}{ 5-6.99 years old } & \multicolumn{3}{|c|}{ 11-12.99 years old } \\
\hline & LL & HL & $\mathrm{p}$ & LL & HL & $\mathrm{p}$ \\
\hline & 3095 & 212 & & 4130 & 267 & \\
\hline Weight (kg) & $23.5 \pm 4.8$ & $21.1 \pm 3$ & $<0.0001^{*}$ & $43.4 \pm 11.1$ & $37.3 \pm 8$ & $<0.0001^{*}$ \\
\hline Height (m) & $1.18 \pm 0.1$ & $1.15 \pm 0.1$ & $<0.0001^{*}$ & $1.46 \pm 0.1$ & $1.42 \pm 0.1$ & $<0.0001^{*}$ \\
\hline BMI & $16.7 \pm 2.6$ & $15.9 \pm 1.9$ & $<0.0001^{*}$ & $20.1 \pm 4$ & $18.5 \pm 3.1$ & $<0.0001^{*}$ \\
\hline \% OW (IOTF) & 15.1 & 10.8 & $0.1086^{* *}$ & 22.7 & 15 & $0.0043^{* *}$ \\
\hline$\%$ OW (CDC) & 14.7 & 9.4 & $0.0426^{* *}$ & 17.1 & 12.4 & $0.0567^{* *}$ \\
\hline \% OW (WHO) & 17.1 & 13.2 & $0.1698^{* *}$ & 11.6 & 12.7 & $0.6568^{* *}$ \\
\hline \% OB (IOTF) & 9.4 & 4.2 & $0.0152^{* *}$ & 10.5 & 3 & $0.0001^{* *}$ \\
\hline$\%$ OB (CDC) & 15.8 & 9 & $0.0105^{* *}$ & 17.2 & 5.6 & $<0.0001^{* *}$ \\
\hline$\%$ OB (WHO) & 30.6 & 18.9 & $0.0004^{* *}$ & 44.1 & 23.6 & $<0.0001^{* *}$ \\
\hline$\%$ OW+OB (IOTF) & 24.5 & 15 & $0.0023^{* *}$ & 33.2 & 18 & $<0.0001^{* *}$ \\
\hline$\% \mathrm{OW}+\mathrm{OB}(\mathrm{CDC})$ & 30.5 & 18.4 & $0.0003^{* *}$ & 34.3 & 18 & $<0.0001^{* *}$ \\
\hline
\end{tabular}

*t test.

$* * \chi^{2}$.

HL: Highlands. LL: Lowlands.

TABLE 3. Mean and standard deviation for weight, height and BMI, and prevalence (\%) of overweight (OW), obesity (OB) and $O W+O B$ as per the references for age and origin in girls

\begin{tabular}{|c|c|c|c|c|c|c|}
\hline \multirow{3}{*}{$\begin{array}{l}\text { Age } \\
\text { Origin } \\
N\end{array}$} & \multicolumn{3}{|c|}{ 5-6.99 years old } & \multicolumn{3}{|c|}{ 11-12.99 years old } \\
\hline & LL & HL & $\mathrm{p}$ & LL & HL & $\mathrm{p}$ \\
\hline & 3225 & 198 & & 4111 & 303 & \\
\hline Weight (kg) & $22.6 \pm 4.5$ & $21.1 \pm 4.3$ & $<0.0001^{*}$ & $43.5 \pm 10.4$ & $38.8 \pm 8$ & $<0.0001^{*}$ \\
\hline Height (m) & $1.17 \pm 0.1$ & $1.15 \pm 0.1$ & $0.0063^{*}$ & $1.48 \pm 0.1$ & $1.44 \pm 0.1$ & $<0.0001^{*}$ \\
\hline $\mathrm{BMI}$ & $16.5 \pm 2.5$ & $15.8 \pm 2.1$ & $0.0001^{*}$ & $19.8 \pm 3.9$ & $18.6 \pm 3$ & $<0.0001^{*}$ \\
\hline \% OW (IOTF) & 15.9 & 9.1 & $0.0137^{* *}$ & 20.5 & 12.9 & $0.0018^{* *}$ \\
\hline$\%$ OW (CDC) & 15.1 & 8.6 & $0.0163^{* *}$ & 16.4 & 10.2 & $0.0058^{* *}$ \\
\hline \% OW (WHO) & 15.6 & 10.1 & $0.0470^{* *}$ & 13.3 & 11.9 & $0.5440^{* *}$ \\
\hline \% OB (IOTF) & 9.3 & 5.6 & $0.1029^{* *}$ & 7.1 & 2 & $0.0010^{* *}$ \\
\hline$\%$ OB (CDC) & 12.1 & 7.6 & $0.0736^{* *}$ & 10.1 & 3.3 & $0.0002^{* *}$ \\
\hline \% OB (WHO) & 25.8 & 15.2 & $0.0012^{* *}$ & 34.3 & 20.1 & $<0.0001^{* *}$ \\
\hline$\%$ OW+OB (IOTF) & 25.2 & 14.7 & $0.0012^{* *}$ & 27.6 & 14.9 & $<0.0001^{* *}$ \\
\hline$\% \mathrm{OW}+\mathrm{OB}(\mathrm{CDC})$ & 27.2 & 16.2 & $0.0009^{* *}$ & 26.5 & 13.5 & $<0.0001^{* *}$ \\
\hline$\% \mathrm{OW}+\mathrm{OB}(\mathrm{WHO})$ & 41.4 & 25.3 & $<0.0001^{* *}$ & 47.6 & 32 & $<0.0001^{* *}$ \\
\hline
\end{tabular}

*t test.

$* * \chi^{2}$.

HL: Highlands. LL: Lowlands. 
TABLE 4. Differences (\%) and agreement (kappa) among the references for age and origin in boys

\begin{tabular}{|c|c|c|c|c|c|c|c|c|}
\hline \multirow{2}{*}{$\frac{\text { Age }}{\text { Origin }}$} & \multicolumn{4}{|c|}{ 5-6.99 years old } & \multicolumn{4}{|c|}{ 11-12.99 years old } \\
\hline & LL & $\mathrm{p}^{*}$ & HL & $\mathrm{p}^{*}$ & LL & $\mathrm{p}^{*}$ & HL & $\mathrm{p}^{*}$ \\
\hline$\%$ OW IOTF/CDC & 0.4 & 0.6846 & 1.4 & 0.7511 & 5.6 & $<0.0001$ & 2.6 & 0.4546 \\
\hline$\%$ OW IOTF/WHO & -2 & 0.0352 & -2.4 & 0.5412 & 11.1 & $<0.0001$ & 2.3 & 0.5195 \\
\hline$\%$ OW CDC/WHO & -2.4 & 0.0109 & -3.8 & 0.2791 & 5.5 & $<0.0001$ & -0.3 & 0.9793 \\
\hline$\%$ OB IOTF/CDC & -6.4 & $<0.0001$ & -4.8 & 0.0727 & -6.7 & $<0.0001$ & -2.6 & 0.2050 \\
\hline$\%$ OB IOTF/WHO & -21.2 & $<0.0001$ & -14.7 & $<0.0001$ & -33.6 & $<0.0001$ & -20.6 & $<0.0001$ \\
\hline$\%$ OB CDC/WHO & -14.8 & $<0.0001$ & -9.9 & 0.0051 & -26.9 & $<0.0001$ & -18 & $<0.0001$ \\
\hline $\mathrm{OW}+\mathrm{OB} \mathrm{IOTF} / \mathrm{CDC}$ & -6 & $<0.0001$ & -3.4 & 0.4189 & -1.1 & 0.3012 & 0 & 0.9103 \\
\hline OW+OB IOTF/WHO & -23.2 & $<0.0001$ & -17.1 & 0.0001 & -22.5 & $<0.0001$ & -18.3 & $<0.0001$ \\
\hline $\mathrm{OW}+\mathrm{OB} \mathrm{CDC} / \mathrm{WHO}$ & -17.2 & $<0.0001$ & -13.7 & 0.0017 & -21.4 & $<0.0001$ & -18.3 & $<0.0001$ \\
\hline Kappa IOTF/CDC & 0.71 & - & 0.71 & - & 0.83 & - & 0.87 & - \\
\hline Kappa IOTF/WHO & 0.32 & - & 0.35 & - & 0.32 & - & 0.39 & - \\
\hline Kappa CDC/WHO & 0.48 & - & 0.52 & - & 0.39 & - & 0.42 & - \\
\hline
\end{tabular}

${ }^{*} \chi^{2}$.

HL: Highlands. LL: Lowlands.

TABLE 5. Differences (\%) and agreement (kappa) among the references for age and origin in girls

\begin{tabular}{lcccccccc}
\hline Age & \multicolumn{3}{c}{ 5-6.99 years old } & & & \multicolumn{3}{c}{ 11-12.99 years old } \\
\hline Origin & LL & $\mathbf{p}^{*}$ & HL & $\mathbf{p}^{*}$ & LL & $\mathbf{p}^{*}$ & \multicolumn{1}{c}{ HL } & $\mathbf{p}^{*}$ \\
\hline \% OW IOTF/CDC & 0.8 & 0.3935 & 0.5 & 0.9986 & 4.1 & $<0.0001$ & 2.7 & 0.3614 \\
\% OW IOTF/WHO & 0.3 & 0.7668 & -1 & 0.8672 & 7.2 & $<0.0001$ & 1 & 0.8024 \\
\% OW CDC/WHO & -0.5 & 0.6014 & -1.5 & 0.7388 & 3.1 & 0.0001 & -1.7 & 0.5907 \\
\% OB IOTF/CDC & -2.8 & 0.0003 & -2 & 0.5491 & -3 & $<0.0001$ & -1.3 & 0.4573 \\
\% OB IOTF/WHO & -16.5 & $<0.0001$ & -9.6 & 0.0030 & -27.2 & $<0.0001$ & -18.1 & $<0.0001$ \\
\% OB CDC/WHO & -13.7 & $<0.0001$ & -7.6 & 0.0263 & -24.2 & $<0.0001$ & -16.8 & $<0.0001$ \\
\% OW+OB IOTF/CDC & -2 & 0.0722 & -1.5 & 0.7842 & 1.1 & 0.2723 & 1.4 & 0.7059 \\
\% OW+OB IOTF/WHO & -16.2 & $<0.0001$ & -10.6 & 0.0120 & -20 & $<0.0001$ & -17.1 & $<0.0001$ \\
\% OW+OB CDC/WHO & -14.2 & $<0.0001$ & -9.1 & 0.0350 & -21.1 & $<0.0001$ & -18.5 & $<0.0001$ \\
Kappa IOTF/CDC & 0.84 & - & 0.8 & - & 0.83 & - & 0.78 & - \\
Kappa IOTF/WHO & 0.37 & - & 0.44 & - & 0.36 & - & 0.37 & - \\
Kappa CDC/WHO & 0.49 & - & 0.59 & - & 0.35 & - & 0.32 & - \\
\hline
\end{tabular}
${ }^{*} \chi^{2}$.

HL: Highlands. LL: Lowlands.

origin. However, the agreement among the IOTF / CDC and the WHO was fair to moderate (Tables 4 and 5).

\section{DISCUSSION}

Students from the HL had significant lower height, weight and BMI when compared to HL students; this confirms the observations of previous investigations. ${ }^{20,21}$ In addition, $\mathrm{OW}$ and OB prevalences were lower in the LL. In general, prevalences obtained with the WHO reference were higher, except for the 11-12.99 year old age group. The greatest agreement was observed between the IOTF and the CDC references.
The same differential altitude distribution in the OW and OB prevalences obtained with the CDC and IOTF references was observed in a study conducted in 2008 on 11431 students aged 12-18 years old from the four regions of Jujuy (Puna, Quebrada, Valle and Ramal). ${ }^{22}$

When comparing the results of this study with a secular trend analysis done between 1995 and 2000 regarding OW and OB of 48533 students aged 4-10 years old and 11-16 years old from the capital city of Jujuy compared to the IOTF and CDC references, an increase in the prevalences of both phenotypes was observed in adolescents. ${ }^{23}$

Since no local references are available in 
relation to the BMI, it is not possible to establish if prevalences obtained in the populations from the highlands of Jujuy (Tables 2 and 3) actually underestimate or overestimate excess fat. Differences observed among the references also seem to be representative of different populations, as discussed below. Disagreements between the CDC and the IOTF,already described in previous studies with students from Jujuy, ${ }^{23}$ ranged between $0.44 \%$ and $2.5 \%$ for overweight and between $1 \%$ and $7 \%$ for obesity, which are lower than those observed in this study (Tables 4and 5).

Differences among references can be interpreted according to: a) the growth pattern of the populations of Jujuy, which is conditioned by altitude and its associated adverse factors; $b$ ) the characteristics of the references.

Differences in the OW and OB prevalences by geographic region can also be interpreted based on the environmental conditions typical of highlands, which interact with the ethnic and genetic background of the Jujuy population. Although it has been established that human populations share a common growth pattern, independently of their ethnicity and geographic location, it cannot be excluded that interpopulation anthropometric disparities reflect actual differences in genetic potential and not only the influence of environmental factors, especially in more advanced stages of ontogenesis. ${ }^{24}$ Despite the effect of hypoxia on human growth is usually minimized and considered marginal, ${ }^{25}$ such effect has been observed in the population of Jujuy even in the prenatal stage. ${ }^{20,26}$

Height accounts for $22 \%$ of the BMI variation in children and adolescents. ${ }^{24,27}$ For this reason, in elevated regions, children at distribution ends (very high or very low values) can be incorrectly classified as overweight or obese. Particularly, variations in the length of lower limbs and sitting height can affect BMI measurement. ${ }^{28}$ Children and adolescents from the Northwest region of Argentina, who grow above 3000 MASL (Catamarca and Jujuy) have a lower standing height, a lower sitting height and shorter lower limbs, and a relative increase of the trunk..$^{29}$

As observed in other populations, ${ }^{10-14}$ the differences in $\mathrm{OW}$ and $\mathrm{OB}$ prevalence among the references are related to sample composition, methods used for generating curves and cutoff values. In relation to sample composition, the main differences lie in the time they were collected, ethnic-geographic origin, screening criteria and health characteristics. In the case of the $\mathrm{WHO}$, for the 2-5 year old population, data are representative of a multicenter, cross-sectional study conducted in children from Pelotas (Brazil), Accra (Ghana), Delhi (India), Oslo (Norway), Muscat (Oman) and David (USA), assessed between 1997 and 2003. For the 5-19 year old population, data were obtained from the National Health and Nutrition Examination Survey (NHANES I), i.e., a USA population assessed in 1971, before the emergence of the obesity epidemics. The IOTF reference sample was made up of data obtained from national, crosssectional growth surveys conducted in Brazil, Great Britain, Hong Kong, the Netherlands, Singapore and the USA between 1963 and 1993,? also before the obesity epidemics. Lastly, the CDC reference sample was made up of national surveys conducted in the USA between 1963 and 1994. Children included in these samples were healthy, but with different growth conditions. While the WHO describes the growth of healthy children under 5 years old in optimal environmental conditions, the CDC and IOTF tables are references that summarize how certain children grow in a specific place and time. Studies conducted in children (0-5 years old) from San Salvador de Jujuy (1200 MASL), comparing the $3^{\text {rd }}, 50^{\text {th }}$ and $97^{\text {th }}$ weight and height percentiles calculated using the LMS method compared to the same percentiles of the CDC and WHO references, indicated that the population from Jujuy has a lower weight and height. ${ }^{23}$ In terms of height, disagreements were higher with the WHO $(1.38 \pm 0.65 \%$ to $1.87 \pm 0.41 \%)$ than with the CDC $(1.09 \pm 0.59 \%$ to $1.66 \pm 0.34 \%)$. The opposite occurred in relation to weight: disagreements were higher as per the CDC $(1.82 \pm 1.56 \%$ to $3.36 \pm 1.4 \%)$ than the WHO (1.12 $\pm 1.28 \%$ to $2.74 \pm 1.49 \%)^{30}$

Discrepancies have emerged in relation to which reference should be used in clinical and epidemiological contexts. Some studies have proposed the IOTF reference as the most adequate for clinical contexts and the WHO standard as the preference at the population level because it provides a better classification of overweight and obese individuals. ${ }^{31}$ The interpretation of BMI variations should be based on prescriptive standards and, if not available, on references that do not underestimate $\mathrm{OW}$ and $\mathrm{OB}$ prevalence. ${ }^{32}$ Although the impact of differences among references could be trivial at a clinical level when monitoring a child individually, it becomes more relevant at an epidemiological 
level when assessing the health of a population, as observed in this study. For this reason, it is necessary to use the same reference for individual assessments (clinical context) and population assessments (epidemiological context) so as to ensure a consistent perspective in both contexts. ${ }^{32}$ However, the results of this study show that such goal is still out of reach because of the over-estimation of fat excess made by the WHO reference compared to the IOTF and the CDC, and because of the greater agreement between the IOTF and the CDC compared to the WHO for all altitudes.

Although the WHO standard (0-5 years old) has been adopted by 125 countries, ${ }^{33}$ including Argentina, the USA, England and other major countries recommend to use local references for children and adolescents. ${ }^{34}$ Studies conducted in Latin American populations indicate the same disagreement among references in relation to how OW and OB prevalences are determined, and suggest to exercise caution when using the WHO reference given the ethnic and methodological differences and because it describes growth prescriptively..$^{13,14,19}$ Based on national surveys conducted in the USA (1988-1994), Russia (1992) and China (1991), three references were compared: IOTF, WHO and CDC. Such results are partially similar to those of this study in that, although $\mathrm{OW}+\mathrm{OB}$ prevalence estimations are similar according to the IOTF and CDC references, the WHO shows higher prevalences. However, in general, references show significant differences in OW prevalence. Given the important clinical impact of this diagnosis, authors recommend to be cautious when comparing results based on different references. ${ }^{35}$

One of the limitations of this study is the source of data, which covers only certain age groups by including students who become participants of the education system when starting or ending primary school. Notwithstanding, information related to the age groups considered in this study ( 5 to 6.99 and 11 to 12.99 years old) is referred to as "census data" because it covers an important percentage of the population from Jujuy in these age groups attending public and private schools (seeTable 1). The results of this study comprise two fundamental times of the growth process: childhood and the beginning of adolescence, and are consistent with those found in students of different ages from Jujuy. ${ }^{22}$

Until a greater consensus is achieved regarding the use of references, student populations should be assessed by comparison with different criteria. At the same time, studies on body composition should be encouraged so as to verify the sensitivity and specificity of criteria and BMI cutoff values, depending on the references, as predictors of body fat percentage and morbidity and mortality, which at present are uncommon in students. ${ }^{17,31}$ However, based on the fact that, as indicated by the kappa test, a greater agreement is observed between the CDC and IOTF references, and that the IOTF includes populations not only from major countries and is more recent than the other standards, the IOTF reference should be chosen for epidemiological studies on obesity among students.

\section{CONCLUSIONS}

A lower OW and OB prevalence was observed in students from the HL. The greatest agreement was observed between the IOTF and the CDC references.

\section{Acknowledgements}

This study was partially funded by PICTO 2008-00139 (ANPCYT) and the Universidad Nacional de Jujuy.

\section{REFERENCES}

1. Wang Y, Lobstein T. Worldwide trends in childhood overweight and obesity. Inter J PediatObesity2006;1:11-25.

2. Lobstein T. Prevalence and trends in childhood obesity. In Crawford D, Robert WJ, Ball K, Brug J (Edt). Obesity Epidemiology: From Aetiology to Public Health. Oxford Universtiy Press 2010;3-16.

3. Kovalskys I, Bay L, RauschHerscovici C, Berner E. Prevalencia de obesidad en una población de 10 a 19 años en la consulta pediátrica. Arch Argent Pediatr2003;101(6):1-7.

4. Linetzkya B,MorelloP, Virgolinia M, Ferrante D. Resultados de la Primera Encuesta Nacional de Salud Escolar. Argentina. Arch Argent Pediatr2011;109(2):111-116.

5. Bejarano IF, Dipierri J, Alfaro E, Quispe Y, Cabrera G. Evolución de la prevalencia de sobrepeso, obesidad y desnutrición en escolares de San Salvador de Jujuy.Arch Argent Pediatr 2005;103(2):101-109.

6. Albala C,Corvalan C. Epidemiology of obesity in children in South America. In: Moreno LA, Pigeot I, Ahrens W (Editors). Epidemiology of Obesity in Children and Adolescents. Springer Series onEpidemiology and PublicHealth 2011;2(1): 95-110.

7. Cole TJ, Bellizzi MC, Flegal KM, Dietz WH. Establishing a standard definition for child overweight and obesity worldwide: international survey. BMJ 2000;320:1240.

8. Kuczmarski RJ, Ogden CL, Guo SS, Grummer-Strawn LM, Flegal KM, Mei Z, Wei R, Curtin LR, Roche AF, Johnson CL. CDC Growth Charts for the United States: Methods and development. National Center for Health Statistics. Vital Health Stat. 2000;11(246):1-190.

9. De Onis M, Garza C, Victora CG, Bhan MK, Norum K, editores invitados. WHO. The WHO MulticentreGrowth Reference Study (MGRS). Available athttp://www.who. int/childgrowth/mgrs [Accessed on: May 15, 2012]. 
10. Monasta L, Lobstein T, Cole TJ, Vignerová J, Cattaneo A. Defining overweight and obesity in pre-school children: IOTF reference or WHO standard? ObesityRev 2011;12:295_ 300.

11. Baya Botti A, Pérez-Cueto FJA, Vásquez Monllor PA, Kolsteren PW. International BMI-for-age references underestimate thinness and overestimate overweight and obesity in Bolivian adolescents.NutrHosp 2010;25(3):428-436.

12. Shields M, Tremblay MS. Canadian childhood obesity estimates based on WHO, IOTF and CDC cut-points. Int J PedObes2010;5:265-273.

13. Padula G, Salceda S. Comparación entre referencias de las prevalencias de sobrepeso y obesidad, estimadas a través del Índice de Masa Corporal, en niños de Argentina. Archivos Latinoamericanos de Nutrición (ALAN) 2008;58(4):330-335.

14. Kovalskys I, Rausch Herscovici C, De Gregorio MJ. Nutritional status of school-aged children of Buenos Aires, Argentina: data using three references. J Pub Health 2010;33(3):403-411.

15. Flegal, KM, Ogden, CL. Childhood obesity: are we all speaking the same language?. Advances in Nutrition: An International Review Journal 2011;2(2),159S-166S.

16. Freedman DS, Khan LK, Serdula MK, Dietz WHet al. Interrelationships among childhood BMI, childhood height and adult obesity: the Bogalusa Heart Study. Int J Obes 2004;28:10-16.

17. Flegal KM, Ogden CL. High body mass index, overweight and obesity in children: definitions, terminology and interpretation. In: O'Dea JA. Eriksen M(Editors). Childhood Obesity Prevention: International Research. Controversies and Interventions. Oxford UniversityPress 2010;3-17.

18. Ministerio deSalud. ManualdeImplementación. Programa de Sanidad Escolar. Available at http://www.msal.gov. ar/index.php/programas-y-planes / 229-programa-desanidad-escolar. [Accessed on: June 9, 2012].

19. Cordeiro Barbosa Filho V, Bianchini de Quadros TM, de Souza EA, PinheiroGordia A, Campos W. A utilização do critério da Organização Mundial de Saúde para classificação do estado nutricional emcrianças. Motriz, Rio Claro 2010;16(4):811-819.

20. Bejarano IF, Dipierri JE, Alfaro EL, Quispe Y, Quero L, Abdo G, Vazquez ME. Patrón de crecimiento y evaluación nutricional dela población infantiljujeña. Cuadernos FHYCS 2004;22:195-210.

21. Bejarano IF, Dipierri JE, Andrade A, Alfaro EL. Geographic altitude, surnames, and height variation of Jujuy (Argentina) conscripts. Am J PhysAnthropol 2009;138:158-163.

22. Dipierri JE, Bejarano IF, Alfaro EL, Cabrera G, Moreno Romero S, Tanuz MH, Marrodán Serrano MD. Prevalencia de sobrepeso y obesidad en poblaciones de altura de la provincia de Jujuy (Argentina). En: JL Nieto, JA Obón y $S$ Baena (Editores): Genes, ambiente y enfermedades en poblaciones humanas. Editado por Prensas Universitarias de Zaragoza; 2008: 521-530.
23. Bejarano I, Dipierri JE, Alfaro EL, Quispe Y, Cabrera G. Evolución de la prevalencia de sobrepeso, obesidad y desnutrición en escolares de San Salvador de Jujuy. ArchArgPed 2005;103(2):101-109.

24. Butte NF, Garza C, de Onis M. Evaluation of the feasibility of international growth standards for school-aged children and adolescents.J Nutr 2007;137(1):153-7.

25. OPS. Informe de la Reunión de Expertos sobre el Uso de los Patrones Internacionales de Crecimiento Infantil en Poblaciones Alto-Andinas. Lima 21 y 22 de Noviembre 2011.

26. Álvarez PB, Dipierri JE, Bejarano IF, Alfaro EL. Variación altitudinal del peso al nacer en la provincia de Jujuy. ArchArgPediatr 2002;100(6):440-447.

27. Metcalf SB, Hosking J, Frémeaux AE, Jeffery AN et al. $\mathrm{BMI}$ was right all along: taller children really are fatter (implications of making childhood BMI independent of height) EarlyBird 48. Int J Obes 2011;35:541-547.

28. Deurenberg P, Deurenberg Yap M, Wang J, Lin FP, Schmidt $\mathrm{G}$. The impact of body build on the relationship between body mass index and percent body fat. Int J Obes 1999;23:537-542.

29. Lomaglio DB, Dip NB, Kriscautsky N, Bejarano IF, Alfaro EL, Dipierri JE, Marrodan MD, Mesa MS. Componentes de la estatura en escolares residentes a distintos niveles altitudinales del Noroeste Argentino. En: Gutiérrez Redomero E, SanchezAndres A, Galera Olmo V (Eds.). Diversidad Humana y Antropología Aplicada. Universidad de Alcalá de Henares, 2010;189-198.

30. Alfaro EL, Vázquez ME, Bejarano IF, Dipierri JE. The LMS method and weight and height centiles in Jujuy (Argentina) children. HOMO 2008;59:223-234.

31. De Sousa Lopes HM. Diagnostic accuracy of CDC, IOTF and WHO criteria for obesity classification, in a Portuguese school-aged children population.Maestrado en Saúde Pública. Universidad do Porto. Facultade de Medicina. Instituto de Ciências Biomédicas Abel Salazar. 2012. [Available at: http://repositorio-aberto. up.pt/bitstream /10216/62314/3/Hugo \%20de \%20 Sousa \%20LopesTeseDiagnostic\%20accuracy $\% 20$ of $\% 20$ CDC $\% 20$ IOTF $\% 20$ and $\% 20$ WHO $\% 20$ criteria $\% 20$ for $\% 20$ obesity $\% 20$ classification $\% 20$ in $\% 20$ a $\% 20$ Portuguese $\% 20$ schoolaged $\% 20$ children $\% 20$ population $\% 20$ Mestrado $\% 20$ em\%20Sade\%20Pblica.pdf] [Accessed on: June 7, 2012].

32. De Onis M. Growth curves for school age children and adolescents.IndianPediatr 2009;46(6):463-5.

33. De Onis M, Onyango A, BorghiE,Siyam A, Blössner M, Lutter C. Worldwide implementation of the WHO Child Growth Standards. Pub HealthNutr 2012;15(9):1-8.

34. Grummer-Strawn LM, Reinold C, Krebs NF. Use of World Health Organization and CDC Growth Charts for children aged 0-59 months in the United States. MMWR RecommRep 2010;59:1-15

35. Wang Y, Wang JQ. A comparison of international references for the assessment of child and adolescent overweight and obesity in different populations. Eur J CliNutr 2002;56, 973-982. 